\title{
Infused autograft lymphocyte-to-monocyte ratio and survival in T-cell lymphoma post- autologous peripheral blood hematopoietic stem cell transplantation
}

\author{
Luis F. Porrata, David J. Inwards, Stephen M. Ansell, Ivana N. Micallef, Patrick B. Johnston, William J. Hogan \\ and Svetomir N. Markovic
}

\begin{abstract}
Background: The infused autograft lymphocyte-to-monocyte ratio (A-LMR) is a prognostic factor for survival in B-cell lymphomas post-autologous peripheral hematopoietic stem cell transplantation (APHSCT). Thus, we set out to investigate if the A-LMR is also a prognostic factor for survival post-APHSCT in T-cell lymphomas.

Methods: From 1998 to 2014, 109 T-cell lymphoma patients that underwent APHSCT were studied. Receiver operating characteristic (ROC) and area under the curve (AUC) were used to identify the optimal cut-off value of A-LMR for survival analysis and $k$-fold cross-validation model to validate the A-LMR cut-off value. Univariate and multivariate Cox proportional hazard models were used to assess the prognostic discriminator power of A-LMR.

Results: ROC and AUC identified an A-LMR $\geq 1$ as the best cut-off value and was validated by $k$-fold cross-validation. Multivariate analysis showed A-LMR to be an independent prognostic factor for overall survival (OS) and progression-free survival (PFS). Patients with an A-LMR $\geq 1.0$ experienced a superior OS and PFS versus patients with an A-LMR $<1.0$ [median OS was not reached vs 17.9 months, 5-year OS rates of $87 \%$ (95\% confidence interval (Cl), $75-94 \%$ ) vs $26 \%$ (95\% Cl, 13-42\%), $p<0.0001$; median PFS was not reached vs 11.9 months, 5-year PFS rates of $72 \%$ (95 \% Cl, 58-83\%) vs $16 \%(95 \% \mathrm{Cl}, 6-32 \%), p<0.0001]$.
\end{abstract}

Conclusions: A-LMR is also a prognostic factor for clinical outcomes in patients with T-cell lymphomas undergoing APHSCT.

Keywords: Autograft absolute lymphocyte-to-monocyte count ratio, Survival, Autologous peripheral hematopoietic stem cell transplantation, T-cell lymphomas

\section{Introduction}

The absolute lymphocyte count (ALC), as a surrogate marker of host immunity, and the absolute monocyte count (AMC), as a surrogate marker of tumor microenvironment, have been reported to be prognostic factors in B-cell lymphomas [1-5]. Similarly, recent studies have shown that both the ALC and AMC have the prognostic ability to predict clinical outcomes in T-cell lymphomas [6-8]. In autologous peripheral hematopoietic stem cell transplantation (APHSCT), day 15 absolute lymphocyte

\footnotetext{
*Correspondence: porrata.luis@mayo.edu

Division of Hematology, Department of Medicine, Mayo Clinic, 200 first St. SW, Rochester, MN 55905, USA
}

count (ALC-15) recovery has been associated with improved survival post-transplant not only in B-cell lymphomas $[9,10]$ but also in T-cell lymphomas [11]. ALC-15 recovery directly depends on the amount of autograft absolute lymphocyte count (A-ALC) collected during stem cell collection and infused in conjunction with stem cells [12-14]. Furthermore, the day-15 absolute monocyte count (AMC-15) is also related to the amount of autograft absolute monocyte count (A-AMC) collected and infused to patients undergoing APHSCT [15]. Both ALC-15 and AMC-15 have been reported to affect survival postAPHSCT [15]. We combined the A-ALC and the A-AMC as a simple biomarker integrating the host immunity 
(i.e., A-ALC) and tumor microenvironment (i.e., A-AMC) into the autograft lymphocyte-to-monocyte ratio (A-LMR) and reported that A-LMR directly affects clinical outcomes in both diffuse large B-cell lymphoma [16] and classical Hodgkin lymphoma [17] patients undergoing APHSCT. Thus, we set out to investigate if the A-LMR also affects survival in T-cell lymphoma patients undergoing APHSCT.

\section{Results}

\section{Patients' characteristics}

The median age at the time of transplant for this cohort of 109 T-cell lymphoma patients was 56 years (range: 19-77 years). The distribution of additional baseline characteristics for these patients is presented in Table 1 . The median follow-up for the entire cohort was 21.5 months (range: 1-147.8 months) and for the living patients $(N=70)$ was 39.6 months (range: $1.8-147.8$ months). Fifty-eight (53\%) of the patients received their APHSCT up front after finishing induction chemotherapy. Two patients received SMILE (methotrexate, leucovorin, ifosfamide, dexamethasone, etoposide, and pegaspargase) chemotherapy and the rest CHOP (cyclophosphamide, doxorubicin, vincristine, and prednisone) chemotherapy as their induction chemotherapy. The salvage chemotherapy included CDE, DHAP, and ICE. The day 100 transplant-related mortality (TRM) for the cohort of patients was $1.8 \%(2 / 109)$. Thirty-one patients died due to relapse/progression of lymphoma. Six patients died of causes unrelated to lymphoma, excluding the two patients that died in the first 100 days post-APHSCT.

\section{Cut-off values for A-ALC, A-AMC, A-LMR, ALC-15, AMC-15, and LMR-15 for survival analysis}

Receiver operating characteristic (ROC) curves and area under the curve (AUC) were used to determine the optimal cut-off points for A-ALC, A-AMC, A-LMR, ALC-15, AMC-15, and day 15 lymphocyte/monocyte ratio postautologous peripheral hematopoietic stem cell transplantation (LMR-15) based on their utility as a marker for the clinical binary outcome of death/survival. The A-LMR $\geq 1$ had an AUC of 0.79 (95\% confidence interval (CI), 0.73$0.85)$ with a sensitivity of $70 \%$ (95 \% CI, 66-76\%) and specificity of $87 \%$ (95\% CI, 83-91\%), $p<0.003$ (Fig. 1a). The A-ALC $\geq 0.5 \times 10^{9}$ cells $/ \mathrm{kg}$ had an AUC of $0.69(95 \%$ CI, 0.61-0.77) with a sensitivity of $78 \%(95 \% \mathrm{CI}, 70-$ $86 \%$ ) and specificity of $68 \%$ (95\% CI, 59-77\%), $p<0.04$. The A-AMC $<0.6 \times 10^{9}$ cells $/ \mathrm{kg}$ had an AUC of 0.71 (95\% CI, 0.62-0.80) with a sensitivity of $64 \%(95 \% \mathrm{CI}$, $55-75 \%$ ) and specificity of $75 \%$ (95\% CI, 67-83\%), $p<$ 0.0006 . The ALC-15 $\geq 500$ cells/ $\mu$ had an AUC of 0.78 (95\% CI, 0.70-0.86) with a sensitivity of $77 \%(95 \% \mathrm{CI}$, 69-85\%) and specificity of $78 \%$ (95\% CI, 70-86 \%), $p<$ 0.0001 . The AMC- $15<500$ cells/ $\mu$ l had an AUC of 0.66 (95\% CI, 0.59-0.73) with a sensitivity of $63 \%$ (95\% CI,
54-72\%) and specificity of $84 \%$ (95\% CI, 77-91\%), $p<$ 0.01 . The LMR-15 $\geq 1$ had an AUC of 0.82 (95\% CI, 0.730.89 ) with a sensitivity of $75 \%$ (95\% CI, 67-83\%) and specificity of $81 \%$ (95\% CI, 74-88\%), $p<0.0001$. An internal validation of A-LMR, A-ALC, A-AMC, ALC-15, AMC-15, and LMR-15 performances as markers for the clinical binary outcomes of death/survival was performed using $k$-fold cross-validation with $k=10$. We obtained an average AUC of 0.80 (95\%CI, 0.73-0.88) over the ten validation sets for A-LMR with a standard deviation of \pm 0.02 . We report the ROC for the complete dataset used in the tenfold procedure, by collecting the A-LMR obtained on each fold. For A-LMR, the cross-validation ROC (Fig. 1b) showed an AUC of 0.80 (95 \% CI, 0.680.92). The similar areas under the curves from the empirical ROC and the cross-validation ROC, as well as for both overall survival (OS) (Fig. 2a) and progression-free survival (PFS) (Fig. 2b) an A-LMR $\geq 1$ was the point of change for the hazard ratio from favorable to unfavorable, support the use of $\mathrm{A}-\mathrm{LMR} \geq 1$ as the cut-off value as marker of the binary clinical outcome of death/survival. In similar fashion, we obtained an average AUC for A-ALC of 0.67 (95 \% CI, 0.59-0.75), A-AMC of 0.68 (95\% CI, 0.60-0.76), ALC-15 of 0.76 (95 \% CI, 0.68-0.84), AMC-15 of 0.67 (95\% CI, 0.60-0.74), and LMR-15 of 0.83 (95\% $\mathrm{CI}, 0.76-0.90)$. We report the ROC for the complete dataset used in the tenfold procedure, by collecting the A-ALC, A-AMC, ALC-15, AMC-15, and LMR-15 obtained on each fold. For A-ALC, the cross validation ROC showed an AUC of 0.68 (95\%CI, 0.61-0.75), for A-AMC of 0.69 (95\% CI, 0.61-0.78), for ALC-15 of 0.77 (95\% CI, 0.69-0.85), for AMC-15 of 0.68 (95\% CI, 0.61-0.75), and for LMR-15 of 0.84 (95\% CI, 0.770.91). The close values of AUC from the empirical ROC and the cross-validation ROC support the use of AALC $\geq 0.5 \times 10^{9}$ cells $/ \mathrm{kg}, \mathrm{A}-\mathrm{AMC}<0.6 \times 10^{9}$ cells $/ \mathrm{kg}$, ALC- $15 \geq 500$ cells $/ \mu \mathrm{l}$, AMC- $15<500$ cells $/ \mu \mathrm{l}$, and LMR-15 $\geq 1$ as the cut-off values to test the binary clinical outcome of death/survival.

\section{Correlation between A-ALC and ALC-15, A-AMC and AMC-15, and A-LMR and LMR-15}

In B-cell lymphomas undergoing APHSCT, we reported a positive correlation between A-ALC and ALC-15, AAMC and AMC-15, and A-LMR and LMR-15. In this cohort of T-cell lymphoma patients, a strong positive correlation was also observed between A-ALC and ALC$15(R=0.5, p<0.0001)$ (Fig. 3a), between A-AMC and AMC-15 $(R=0.5, p<0.0001)$ (Fig. 3b), and between ALMR and LMR-15 ( $R=0.7, p<0.0001)$ (Fig. 3c). No correlation was identified between the infused CD34 and ALC-15 $(R=0.01, p=0.9)$, infused CD34 and AMC-15 $(R=0.13$, $p=0.2)$, or infused CD34 and LMR-15 $(R=0.10, p=0.3)$. 
Table 1 Baseline characteristics in the training set and validation set

\begin{tabular}{|c|c|c|c|}
\hline Variable & $\begin{array}{l}\text { A-LMR } \geq 1 \\
(N=59)\end{array}$ & $\begin{array}{l}\text { A-LMR }<1 \\
(N=50)\end{array}$ & $p$ value \\
\hline
\end{tabular}

At diagnosis

Age, years, median (range)

Gender

Male

Female

LDH (U/L), median (range)

Extra-nodal site

0
1
2
B symptoms
Yes
No
Stage
I
I|
II
IV

Bone marrow involvement

Yes

No

Bulky disease

Yes

No

Hemoglobin $(\mathrm{g} / \mathrm{dl})$, median (range)

Platelets $\times 10^{9} /$, median (range)

IPI score

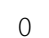

1

1

2

3

4

5

Performance status

0
1
2
3

T-cell lymphoma histologies Anaplastic large cell
0.2

$38(64 \%) \quad 25(50 \%)$

$21(36 \%) \quad 25(50 \%)$

$211 \quad 276.5$

(116-928) (137-1539)

0.04

0.05

$7(12 \%) \quad 6(12 \%)$

$49(83 \%) \quad 34(68 \%)$

$3(5 \%) \quad 10(20 \%)$

0.9

$17(29 \%) \quad 15(30 \%)$

$42(71 \%) \quad 35(70 \%)$

$<0.001$

$\begin{array}{cc}2(3 \%) & 1(2 \%) \\ 26(44 \%) & 5(10 \%) \\ 9(15 \%) & 12(24 \%) \\ 22(38 \%) & 32(64 \%)\end{array}$

0.5

$15(25 \%) \quad 16(32 \%)$

$44(75 \%) \quad 34(68 \%)$

$3(5 \%) \quad 6(6 \%)$

$56(95 \%) \quad 47(94 \%)$

$12.5 \quad 12.5$

(8.1-13.1) (6.6-16.9)

$231 \quad 214$

(14-626) (31-719)

$13(22 \%) \quad 2(4 \%)$

19 (32\%) $12(24 \%)$

$17(29 \%) \quad 18(36 \%)$

$8(13 \%) \quad 10(20 \%)$

$1(2 \%) \quad 7(14 \%)$

$1(2 \%) \quad 1(2 \%)$

0.3

$7(12 \%) \quad 4(8 \%)$

$45(76 \%) \quad 43(86 \%)$

$5(8 \%) \quad 3(6 \%)$

$2(45 \%) \quad 0(0 \%)$

$10(17 \%) \quad 5(13 \%)$

0.8

0.9
Table 1 Baseline characteristics in the training set and validation set (Continued)

$\begin{array}{lcc}\text { Angioimmunoblastic } & 15(25 \%) & 15(27 \%) \\ \text { Enteropathy-associated } & 6(10 \%) & 3(6 \%) \\ \text { Hepatosplenic } & 1(2 \%) & 1(2 \%) \\ \text { NKTT } & 7(12 \%) & 6(12 \%) \\ \text { Panniculitis } & 4(7 \%) & 3(6 \%) \\ \text { Peripheral } & 16(27 \%) & 17(34 \%)\end{array}$

IPI factors

Age, years

60

$\leq 60$

$\mathrm{LDH}(\mathrm{U} / \mathrm{L})$

Normal

Abnormal

Performance status

1

$\leq 1$

Extra-nodal disease

1

$\leq 1$

Stage

I/II

III/IV

IPI index

2

$\leq 2$

Initial chemotherapy

$\mathrm{CHOP}$

SMILE

Salvage chemotherapy $(N=51)$

$\begin{array}{ll}18(31 \%) & 20(40 \%) \\ 41(69 \%) & 30(60 \%) \\ 34(58 \%) & 18(36 \%) \\ 25(42 \%) & 32(64 \%)\end{array}$

$7(12 \%) \quad 3(6 \%)$

$52(88 \%) \quad 47(94 \%)$

$3(5 \%) \quad 10(20 \%)$

$56(95 \%) \quad 40(80 \%)$

$<0.001$

$28(47 \%) \quad 6(12 \%)$

$31(53 \%) \quad 44(88 \%)$

0.03

10 (17\%) $18(36 \%)$

$49(83 \%) \quad 32(64 \%)$

0.9

$58(98 \%) \quad 49(98 \%)$

$1(2 \%) \quad 1(2 \%)$

0.2

$2(9 \%) \quad 0(0 \%)$

$5(21 \%) \quad 8(29 \%)$

$16(70 \%) \quad 20(71 \%)$

ICE

Up-front transplant

Yes

No

$36(61 \%) \quad 22(44 \%)$

$23(39 \%) \quad 28(56 \%)$

At transplant

Pre-transplant clinical status

$<0.001$

$C R$
$P R$

$51(86 \%) \quad 25(50 \%)$

$8(15 \%) \quad 25(50 \%)$

Plerixafor

Yes

$21(36 \%) \quad 19(38 \%)$

No

Infused CD34, median (range)

$5.42 \quad 5.12$

(2.25-13.44) (2.04-15.65) 
Table 1 Baseline characteristics in the training set and validation set (Continued)

\begin{tabular}{cccc}
\hline Number of collections & & & 0.08 \\
1 & $7(12 \%)$ & $12(24 \%)$ & \\
2 & $19(32 \%)$ & $15(30 \%)$ & \\
3 & $19(32 \%)$ & $9(18 \%)$ & \\
4 & $7(12 \%)$ & $11(22 \%)$ & \\
5 & $1(2 \%)$ & $2(4 \%)$ & \\
6 & $3(5 \%)$ & $0(0 \%)$ & \\
7 & $2(3 \%)$ & $0(0 \%)$ & \\
8 & $1(2 \%)$ & $1(2 \%)$ & \\
A-ALC, median (range) & 0.68 & 0.44 & $<0.001$ \\
A-AMC, median (range) & $(0.21-3.83)$ & $(0.06-1.40)$ & \\
& 0.45 & 0.78 & $<0.001$ \\
ALC-15, median (range) & $(0.10-1.42)$ & $(0.20-1.60)$ & \\
& 0.71 & 0.41 & $<0.001$ \\
AMC-15, median (range) & $(0.10-2.31)$ & $(0.10-1.18)$ & \\
& 0.43 & 0.90 & $<0.001$ \\
LMR-15 & $(0.04-1.19)$ & $(0.20-2.31)$ & \\
& 1.71 & 0.57 & $<0.001$ \\
\hline
\end{tabular}

Abbreviations: A-ALC autograft absolute lymphocyte count; $A L C-15$ day 15 absolute lymphocyte count post-autologous peripheral hematopoietic stem cell transplantation; A-AMC autograft absolute monocyte count; AMC-15 day 15 absolute monocyte count post-autologous peripheral hematopoietic stem cell transplantation; $A-L M R$ autograft lymphocyte/monocyte ratio; $C D E$ cyclophosphamide, doxorubicin, and etoposide; $C R$ complete response; CHOP cyclophosphamide, doxorubicin, vincristine, and prednisone; DHAP dexamethasone, cytarabine, and cisplatin; ICE ifosfamide, carboplatin, and etoposide; IPI International Prognostic Index; $L D H$ lactate dehydrogenase; LMR- 15 day 15 lymphocyte/monocyte ratio post-autologous peripheral hematopoietic stem cell transplantation; PR partial response; SMILE methotrexate, leucovorin, ifosfamide, dexamethasone, etoposide, and pegaspargase

\section{Predictors for OS and PFS}

Using the univariate Cox regression analysis, the following variables were predictors for OS: B symptoms, platelets, extra-nodal disease, lactate dehydrogenase (LDH), stage, International Prognostic Index (IPI), complete response (CR) prior to APHSCT, A-ALC, A-AMC, A-LMR, ALC15, AMC-15, and LMR-15 (Table 2). For PFS, the following variables were predictors: hemoglobin, platelets, extra-nodal disease, LDH, stage, IPI, CR prior to APHSCT, A-ALC, A-AMC, A-LMR, ALC-15, AMC-15, and LMR-15 (Table 2). Since extra-nodal disease, LDH, and stage are components of IPI, IPI was only included in the multivariate analysis. Multivariate analysis identified the following predictors for OS and PFS: A-ALC, A-LMR, A-AMC, and CR prior to APHSCT (Table 3). To avoid the problem of colinearity due to the strong positive correlation between A-ALC and ALC-15, A-AMC and AMC-15, and A-LMR and LMR-15, we substituted ALC-15 for A-ALC, AMC-15 for A-AMC, and LMR-15 for A-LMR and tested them against the other predictors (CR prior to APHSCT, extranodal disease, hemoglobin, IPI, LDH, platelets, and stage) in the multivariate analysis. ALC-15, AMC-15, and LMR15 remained independent predictors for OS and PFS: for OS [ALC-15: hazard ratio (HR) of 0.256, $95 \% \mathrm{CI}$, $0.094-0.665, p<0.005$; AMC-15: HR of 0.351, $95 \% \mathrm{CI}$, $0.169-0.820, p<0.01$; and LMR-15: HR of $0.307,95 \%$ CI, 0.102-0.820, $p<0.02$ ] and for PFS [ALC-15: HR of 0.439, $95 \%$ CI, 0.200-0.967, $p<0.04$; AMC-15: HR of 0.383, $95 \%$ CI, 0.175-0.867, $p<0.01$; and LMR-15: HR of 0.408, $95 \%$ CI, 0.200-0.823, $p<0.01$ ].

\section{Survival outcomes based on A-LMR}

Using the cut-off value of 1.0 for the A-LMR obtained from the empiric ROC and subsequently validated by $k$-fold cross-validation, we tested A-LMR $\geq 1$ for OS and PFS. We
A

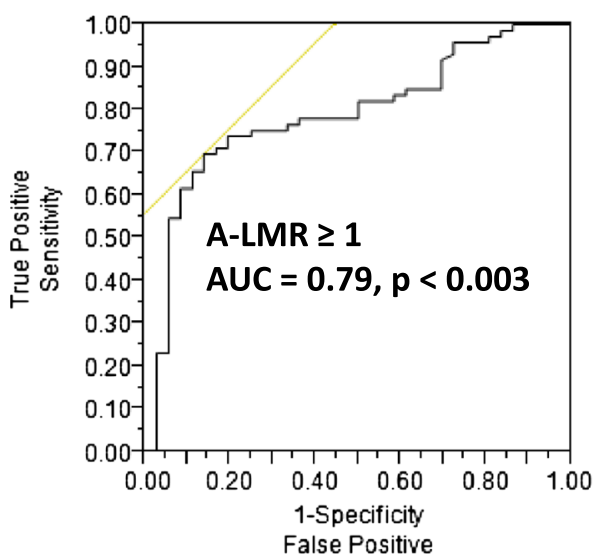

B

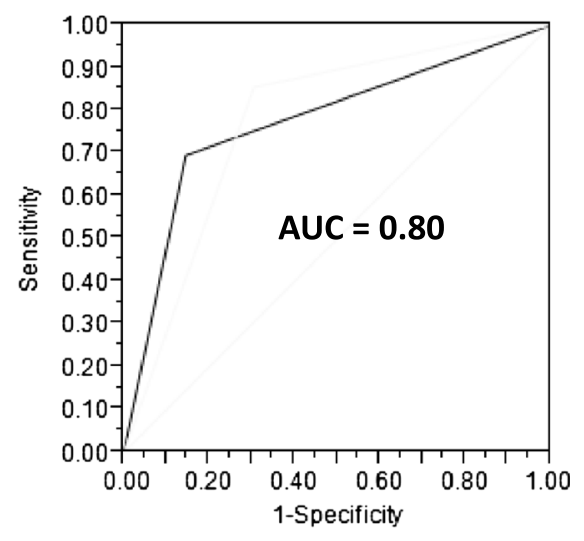

Fig. 1 a Receiver operating characteristics (ROC) curves and area under the curve (AUC) for autograft lymphocyte-to-monocyte ratio (A-LMR). b $k$-fold cross-validation ROC and AUC for A-LMR in the training set 

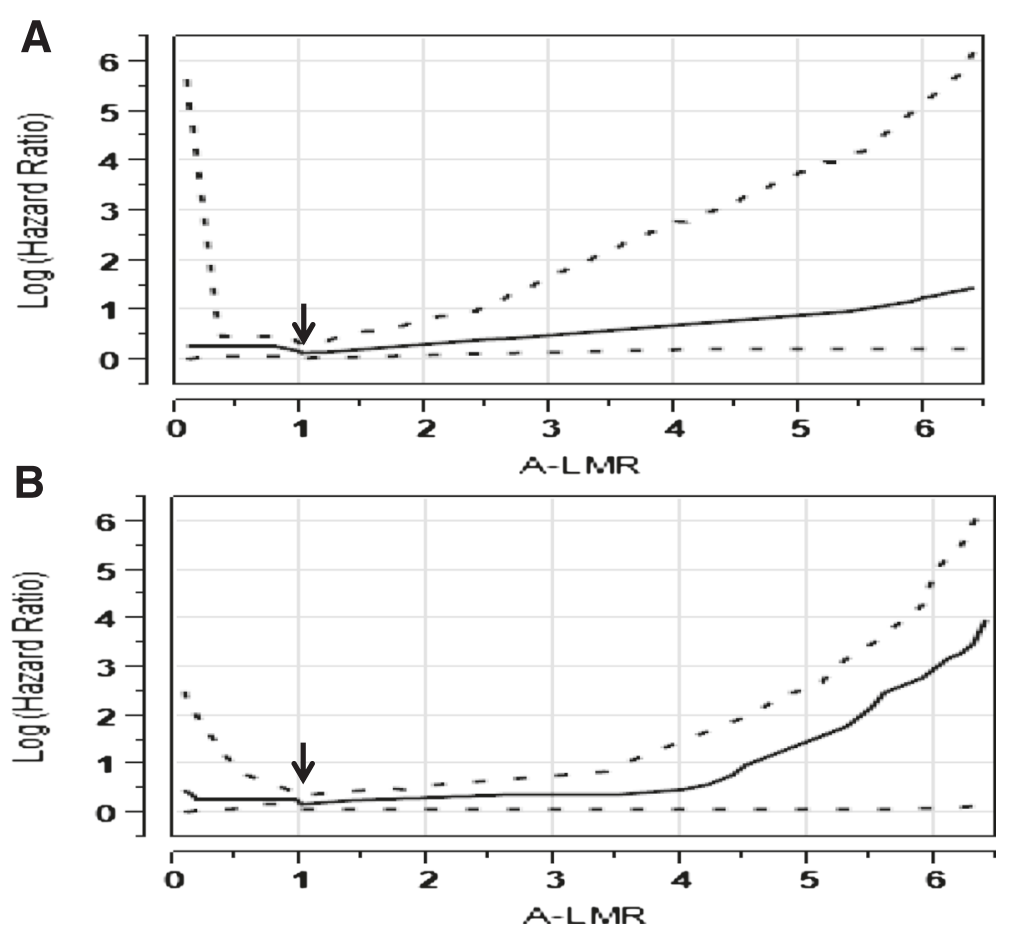

Fig. 2 a Determination of hazard ratio associated with different levels of autograft lymphocyte-to-monocyte ratio (A-LMR) as a continuous variable for overall survival. b Determination of hazard ratio associated with different levels of A-LMR as continuous variable for progression-free survival

observed that patients infused with an A-LMR $\geq 1$ compared with patients infused with an A-LMR $<1$ experienced superior OS (Fig. 4a) and PFS (Fig. 4b) [median OS was not reached versus 17.9 months, 5-year OS rates of $87 \%$ (95\% CI, 75-94 \%) versus $26 \%$ (95\% CI, $13 \%-42 \%$ ), p < 0.0001; median PFS was not reached versus 11.9 months, 5-year PFS rates of $72 \%$ (95\% CI, 58-83\%) versus $16 \%$ (95\% CI, 6-32\%), $p<0.0001]$. By histopathological subtype, superior OS and PFS was observed in patients with an A-LMR $\geq 1$ compared with patients with an A-LMR $<1$ diagnosed with peripheral T-cell lymphoma not otherwise specified (NOS) [median OS (Fig. 5a) was not reached versus 18.7 months, 3-year OS rates of $79 \%$ (95\% CI, 70-93\%) versus $46 \%$ (95\% CI, 23-71 \%), $p<0.05$; median PFS (Fig. 5b) was not reached versus 12.2 months, 3-year PFS rates of $60 \%$ (95\% CI, 51-91\%) versus $21 \%$ (95\% CI, 7-47\%), $p<0.0001]$, for angioimmunoblastic T-cell lymphoma [median OS (Fig. 5c) was not reached versus 14.6 months, 3-year OS rates of $92 \%$ (95\% CI, 59-99\%) versus $24 \%$ (95\% CI, 8-54\%), $p<0.0001$; median PFS (Fig. 5d) was not reached versus 11.9 months, 3-year PFS rates of $78 \%$ (95\% CI, 48-93\%) versus $0 \%, p<0.0001]$, and for others [median OS (Fig. 5e) was not reached versus 18.1 months, 3-year OS rates of $88 \%$ (95 \% CI, 70$96 \%$ ) versus $28 \%$ (95\% CI, 10-57 \%), $p<0.05$; median PFS (Fig. 5f) was not reached versus 5.3 months, 3-year PFS rates of $74 \%$ (95\% CI, 64-94\%) versus $28 \%(95 \%$ CI, $12-54 \%), p<0.0001]$.

\section{Discussion}

In B-cell lymphoma, the A-LMR has been reported to be a prognostic factor for survival in patients treated with APHSCT. Thus, we set out to investigate if the A-LMR can impact survival in patients with T-cell lymphomas treated with APHSCT.

In all T-cell lymphoma patients undergoing APHSCT, the infusion of an A-LMR $\geq 1$ was associated with superior OS and PFS. Furthermore, A-LMR showed a homogeneous prognostic role between the histological subtypes, as superior survival was observed in patients with an infused $A-L M R \geq 1$ regardless of the underlying T-cell lymphoma histologies. This observation was observed in subsets of patients categorized by histological subtypes as well. Multivariate analysis revealed the A-LMR to be an independent prognostic factor for survival in T-cell lymphoma patients treated with APHSCT when adjusted for other reported prognostic factors.

The ALC-15 has been reported to be a prognostic factor for survival in B-cell lymphomas treated with APHSCT and has also been reported to be a prognostic factor for survival in T-cell lymphoma patients undergoing APHSCT. The ALC-15 recovery is directly dependent on the amount of collected and infused A-ALC. In this study, as we published in B-cell lymphomas [12], the correlation between A-ALC and ALC-15 was confirmed for the first time in T-cell lymphomas treated with APHSCT. In vitro and clinical studies have reported inhibition of host 


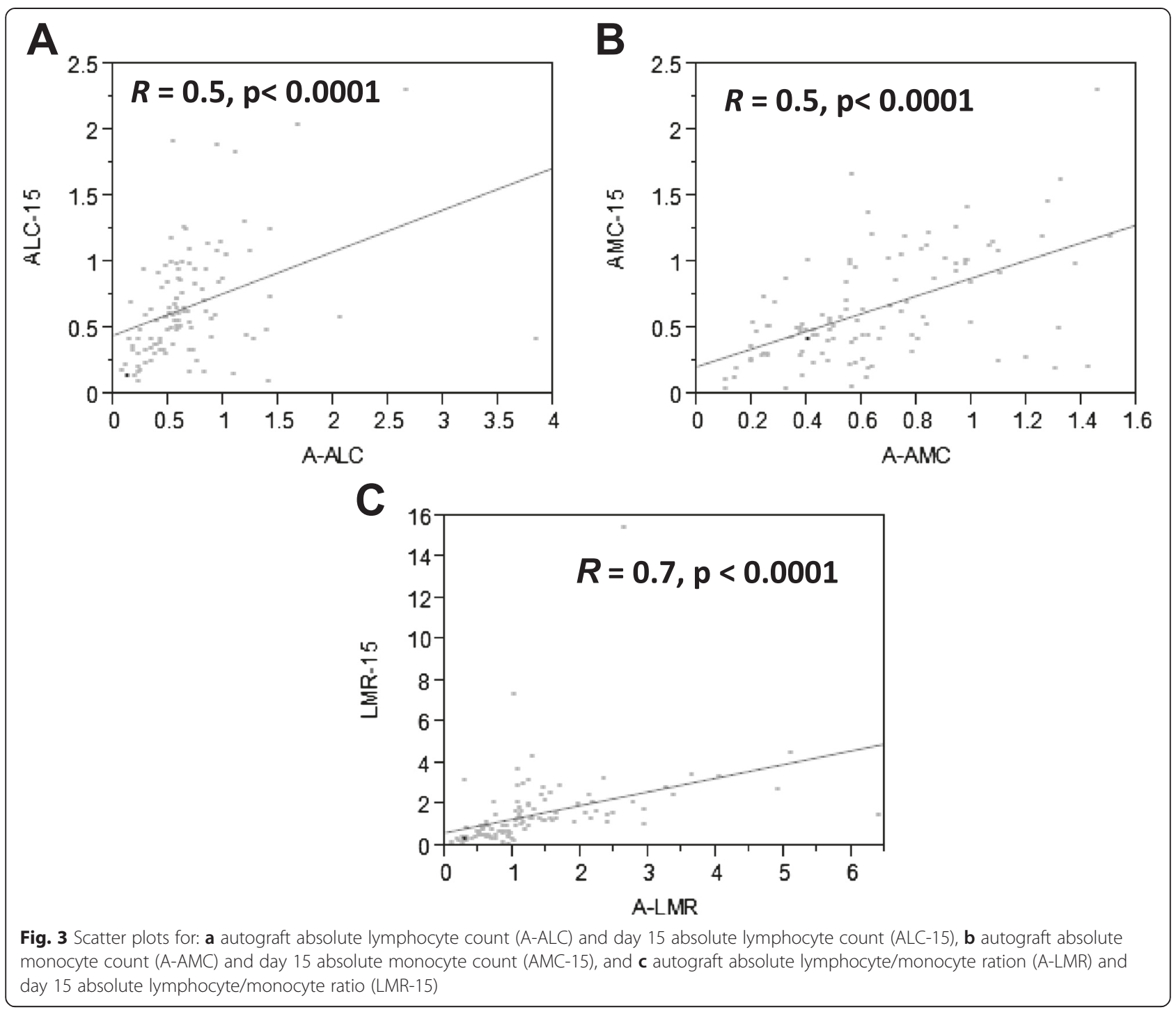

immunity and survival by immunosuppressive monocytes in T-cell lymphoma [18]. In APHSCT, we documented that A-AMC, which directly affects AMC-15 recovery, conveyed a negative prognosis in B-cell lymphomas. We observed the same negative survival effect in T-cell lymphoma patients infused with higher A-AMC and AMC-15 numbers post-APHSCT. As in our previous reports [12, 13, 15], no correlation was identified between the infused CD34 count and ALC-15, AMC-15, or LMR-15 in T-cell lymphoma patients undergoing APHSCT. To our knowledge, this is the first study reporting that the A-LMR, which combined the biomarkers of A-ALC and A-AMC, not only affects ALC-15 and $\mathrm{AMC}-15$ recovery but also survival in T-cell lymphoma patients treated with APHSCT. The possible mechanism addressing the negative survival of patients infused with an A-LMR $<1$ due to the higher content of A-AMC has been addressed in our previous publication [19].
The limitations of our study include being a retrospective study and a small cohort of T-cell lymphomas undergoing APHSCT. The strengths of the study include long-term follow-up of T-cell lymphoma patients treated consecutively with APHSCT at a single institution. This study expands on the previous publications regarding A-ALC and A-AMC by highlighting the importance of the interaction between host immunity and tumor microenvironment, using the simple biomarkers of A-ALC and A-AMC combined in the prognostic factor of A-LMR.

\section{Conclusion}

Finally, the association between A-LMR and survival provides a rationale to develop clinical translational interventions to engineer immunocompetent autografts with direct impact on immune recovery and survival, not only in 
Table 2 Univariate analysis for overall survival (OS) and progression-free survival (PFS)

\begin{tabular}{|c|c|c|c|c|c|c|}
\hline \multirow[t]{2}{*}{ Variable } & \multicolumn{3}{|l|}{ OS } & \multicolumn{3}{|l|}{ PFS } \\
\hline & $\mathrm{HR}$ & $95 \% \mathrm{Cl}$ & $p$ & $H R$ & $95 \% \mathrm{Cl}$ & $p$ \\
\hline Age $>60$ years & 1.532 & $0.784-2.900$ & 0.2 & 1.400 & $0.789-2.422$ & 0.2 \\
\hline Female versus male & 1.153 & $0.606-2.170$ & 0.7 & 1.359 & $0.787-2.342$ & 0.3 \\
\hline B symptoms & 1.919 & $1.094-3.615$ & 0.05 & 1.425 & $0.790-2.485$ & 0.2 \\
\hline Bulky disease & 1.007 & $0.164-3.294$ & 0.9 & 1.109 & $0.270-3.024$ & 0.9 \\
\hline Hemoglobin < $12.0 \mathrm{~g} / \mathrm{dl}$ & 1.636 & $0.862-3.072$ & 0.1 & 1.858 & $1.076-3.193$ & 0.03 \\
\hline Platelet $<150 \times 10^{9} / 1$ & 2.566 & $1.312-4.862$ & 0.007 & 2.890 & $1.671-5.047$ & $<0.001$ \\
\hline Extra-nodal sites > 1 & 3.043 & $1.354-6.197$ & 0.009 & 2.332 & $1.104-4.470$ & 0.03 \\
\hline $\mathrm{LDH}(\mathrm{U} / \mathrm{L})$ & 6.695 & $3.001-17.77$ & $<0.001$ & 4.510 & $2.440-8.989$ & $<0.001$ \\
\hline Performance status > 1 & 1.788 & $0.674-3.972$ & 0.2 & 2.033 & $0.885-4.089$ & 0.09 \\
\hline Stage III/IV & 3.817 & $1.630-11.160$ & $<0.001$ & 2.571 & $1.393-5.431$ & 0.004 \\
\hline $\mid \mathrm{PI}>2$ & 4.442 & $2.342-8.459$ & $<0.001$ & 3.734 & $2.146-6.444$ & $<0.001$ \\
\hline Positive bone marrow & 1.670 & $0.856-3.153$ & 0.1 & 1.294 & $0.709-2.271$ & 0.4 \\
\hline Infused CD34 & 0.893 & $0.758-1.032$ & 0.1 & 0.950 & $0.832-1.070$ & 0.4 \\
\hline CR prior to APHSCT & 0.164 & $0.081-0.314$ & $<0.001$ & 0.186 & $0.106-0.321$ & $<0.001$ \\
\hline A-ALC $\geq 0.5 \times 10^{9} / \mathrm{kg}$ & 0.358 & $0.188-0.676$ & 0.002 & 0.294 & $0.167-0.511$ & $<0.001$ \\
\hline $\mathrm{A}-\mathrm{AMC} \geq 0.6 \times 10^{9} / \mathrm{kg}$ & 3.207 & $1.585-7.175$ & $<0.001$ & 2.254 & $1.285-4.116$ & 0.004 \\
\hline$A-L M R \geq 1$ & 0.155 & $0.066-0.322$ & $<0.001$ & 0.196 & $0.104-0.353$ & $<0.001$ \\
\hline $\mathrm{ALC}-15 \geq 0.5 \mathrm{cells} / \mu \mathrm{l}$ & 0.158 & $0.072-0.304$ & $<0.001$ & 0.246 & $0.139-0.430$ & $<0.001$ \\
\hline AMC $-15 \geq 0.5$ cells $/ \mu l$ & 3.909 & $1.881-9.160$ & $<0.001$ & 2.645 & $1.489-4.918$ & $<0.001$ \\
\hline LMR-15 & 0.143 & $0.061-0.497$ & $<0.001$ & 0.214 & $0.116-0.378$ & $<0.001$ \\
\hline Plerixafor & 0.954 & $0.497-1.925$ & 0.7 & 0.886 & $0.510-1.587$ & 0.8 \\
\hline
\end{tabular}

Abbreviations: $A$-ALC autograft absolute lymphocyte count, $A L C-15$ day 15 absolute lymphocyte count post-autologous peripheral hematopoietic stem cell transplantation, $A-A M C$ autograft absolute monocyte count, $A M C-15$ day 15 absolute monocyte count post-autologous peripheral hematopoietic stem cell transplantation, $A-L M R$ autograft lymphocyte/monocyte ratio, $L M R-15$ day 15 lymphocyte/monocyte ratio post-autologous peripheral hematopoietic stem cell transplantation, $C R$ complete response, IPI International Prognostic Index, $L D H$ lactate dehydrogenase

patients with B-cell lymphomas but also T-cell lymphomas treated with APHSCT.

\section{Materials and methods}

\section{Patient population}

To qualify for the study, patients were required to be candidates for APHSCT with the diagnosis of T-cell lymphoma and have mobilized enough peripheral blood stem cells to proceed with APHSCT (minimum of $2.0 \times$ $10^{6} \mathrm{CD} 34 \mathrm{cells} / \mathrm{kg}$ ). Patients were excluded if they failed to mobilize stem cells, required bone marrow harvest, were infused with both peripheral blood and bonemarrow-harvest-derived stem cells, or participated in stem cell transplantation clinical trials. No patients were lost to follow-up. From 1998 to 2014, 109 T-cell lymphoma patients qualified for the study. All patients gave

Table 3 Multivariate analysis for overall survival (OS) and progression-free survival (PFS)

\begin{tabular}{|c|c|c|c|c|c|c|}
\hline \multirow[t]{2}{*}{ Variable } & \multicolumn{3}{|l|}{ OS } & \multicolumn{3}{|l|}{ PFS } \\
\hline & $\mathrm{HR}$ & $95 \% \mathrm{Cl}$ & $p$ & $\mathrm{HR}$ & $95 \% \mathrm{Cl}$ & $p$ \\
\hline $\mathrm{A}-\mathrm{ALC} \geq 0.5 \times 10^{9} / \mathrm{kg}$ & 0.401 & $0.231-0.972$ & 0.04 & 0.439 & $0.271-0.902$ & 0.03 \\
\hline $\mathrm{A}-\mathrm{AMC}<0.6 \times 10^{9} / \mathrm{kg}$ & 0.502 & $0.100-0.985$ & 0.04 & 0.490 & $0.288-0.911$ & 0.03 \\
\hline$A-L M R \geq 1$ & 0.258 & $0.105-0.561$ & $<0.001$ & 0.298 & $0.112-0.482$ & $<0.001$ \\
\hline CR prior to APHSCT & 0.356 & $0.166-0.731$ & 0.005 & 0.401 & $0.211-0.681$ & 0.008 \\
\hline Hemoglobin $<12 \mathrm{~g} / \mathrm{dl}$ & & & & 1.592 & $0.861-2.935$ & 0.1 \\
\hline$|\mathrm{P}|>2$ & 2.377 & $1.163-4.972$ & 0.02 & 1.398 & $0.705-2.771$ & 0.3 \\
\hline Platelet $<150 \times 10^{9} / \mid$ & 1.297 & $0.627-2.607$ & 0.5 & 1.164 & $0.590-2.268$ & 0.7 \\
\hline
\end{tabular}

Abbreviations: $A$-ALC autograft absolute lymphocyte count, $A-A M C$ autograft absolute monocyte count, $A$-LMR autograft lymphocyte/monocyte ratio, $A-L M R$ autograft lymphocyte/monocyte ratio, $C R$ complete response, IPI International Prognostic Index, $L D H$ lactate dehydrogenase 

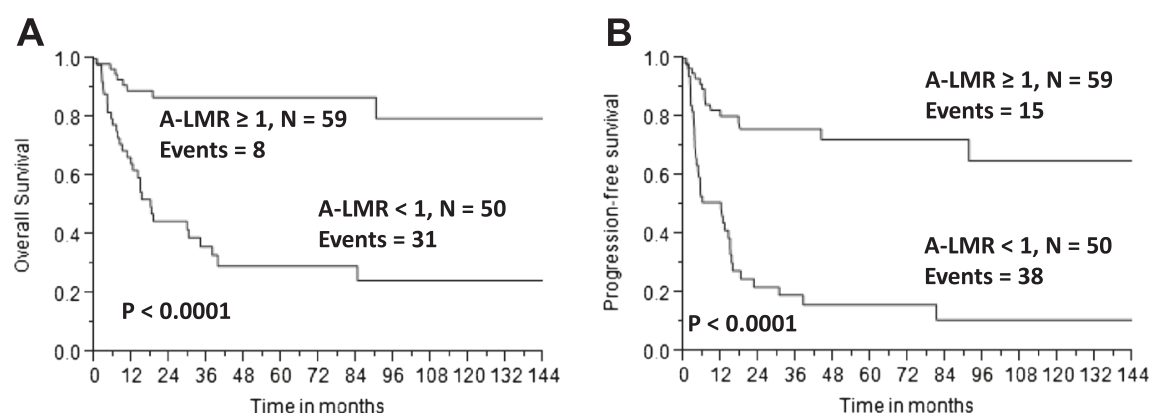

Fig. 4 a Overall survival based on autograft lymphocyte-to-monocyte ratio (A-LMR). b Progression-free survival based on autograft lymphocyte-tomonocyte ratio (A-LMR)

A



C

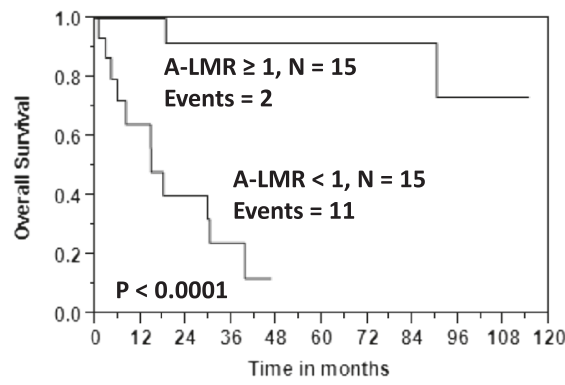

E

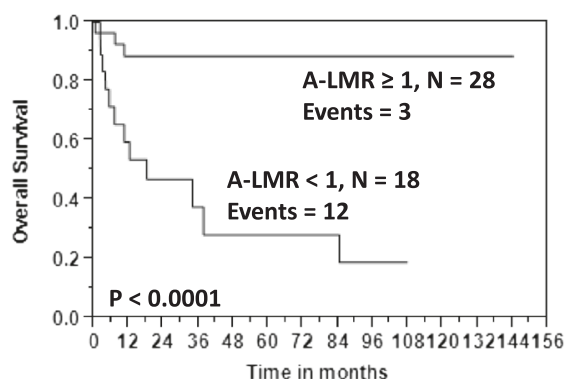

B

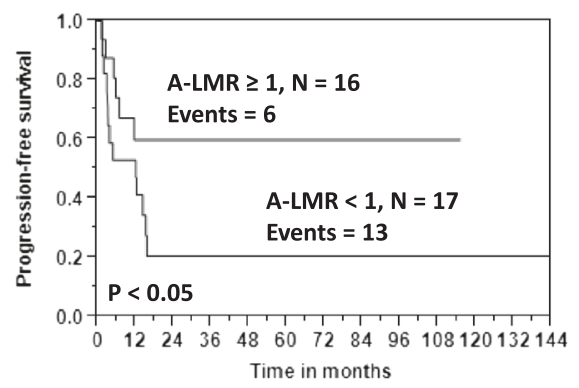

D

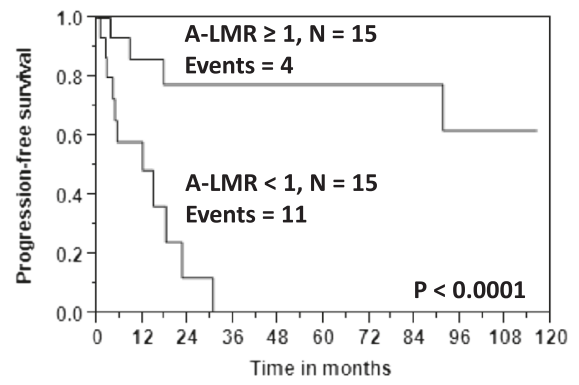

F

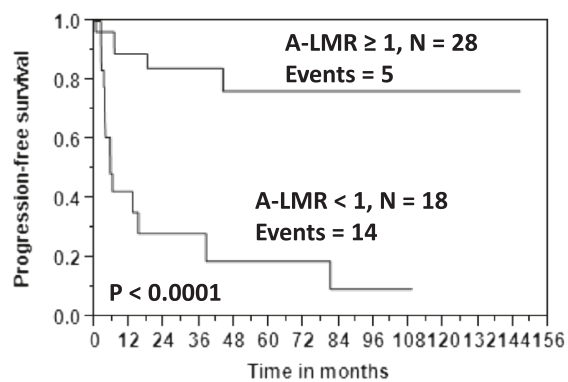

Fig. 5 Overall survival: a peripheral T-cell lymphoma, c angioimmunoblastic T-cell lymphoma, and e others. Progression-free survival: b peripheral T-cell lymphoma, $\mathbf{d}$ angioimmunoblastic T-cell lymphoma, and $\mathbf{f}$ others 
written, informed consent allowing the use of their medical records for medical research. Approval for the retrospective review of these records was obtained from the Mayo Clinic Institutional Review Board and was in accordance with US federal regulations and the Declaration of Helsinki.

\section{End points}

The primary end point of the study was to assess the impact of A-LMR on overall survival (OS) and progressionfree survival (PFS) from the time of APHSCT in patients with T-cell lymphoma. The infused A-ALC for each apheresed unit collection was calculated as follows: A-ALC $=\%$ collection lymphocytes $\times$ (absolute white blood cell (WBC) count $/ \mathrm{kg}$ ). The infused A-AMC for each apheresed unit collection was calculated as follows: A$\mathrm{AMC}=\%$ collection monocytes $\times$ (absolute $\mathrm{WBC}$ count $/ \mathrm{kg})$. The A-LMR was then calculated by dividing the A-ALC by the A-AMC.

\section{Prognostic factors}

The following prognostic factors were evaluated in the study: international prognostic score (IPI) [20] at diagnosis: [age ( $>60$ years), extra-nodal disease $(>1$ site), lactate dehydrogenase (LDH), performance status $(>1)$, and stage]; A-LMR; A-ALC; A-AMC; ALC-15; AMC-15; day 15 lymphocyte-to monocyte ratio (LMR-15); B symptoms; bone marrow involvement at diagnosis; bulky disease $(>10 \mathrm{~cm})$; clinical status prior to APHSCT [complete response $(\mathrm{CR})$ versus partial response $(\mathrm{PR})]$; hemoglobin $(<12 \mathrm{~g} / \mathrm{dl})$ at diagnosis; platelets $\left(<150 \times 10^{9} / \mathrm{l}\right)$ at diagnosis; and infused CD34+ stem cells dose.

\section{Peripheral blood stem cell (autograft) collections}

Patients received granulocyte colony-stimulating factor (G-CSF) for mobilization at a dose of $10 \mu \mathrm{g} / \mathrm{kg}$ daily for 5-7 consecutive days by subcutaneous injection. Once the peripheral blood CD34+ cell count was $\geq 10$ cells $/ \mu \mathrm{l}$ on G-CSF, patients began daily apheresis until a minimum target of $2.0 \times 10^{6} \mathrm{CD} 34$ cells $/ \mathrm{kg}$ was reached. If on day 4 on G-CSF, the peripheral blood CD34 was less than $10 \mathrm{cells} / \mu \mathrm{l}$, the addition of plerixafor $0.24 \mathrm{mg} / \mathrm{kg}$ was allowed.

\section{Conditioning regimen}

All patients were treated with BEAM: BCNU $\left(300 \mathrm{mg} / \mathrm{m}^{2}\right)$ on day -6 , etoposide $\left(100 \mathrm{mg} / \mathrm{m}^{2}\right)$ twice daily from days -5 to -2 , cytarabine $\left(100 \mathrm{mg} / \mathrm{m}^{2}\right)$ twice daily from days -5 to -2 , and melphalan $\left(140 \mathrm{mg} / \mathrm{m}^{2}\right)$ on day -1 .

\section{Response and survival}

Response criteria were based on the guidelines from the International Harmonization Project on Lymphoma [21]. OS was measured from the date of transplant to the date of death or last follow-up. PFS was defined as the time from transplant to the time of progression, relapse, death, or last follow-up.

\section{Statistical analysis}

OS and PFS were analyzed using the approach of Kaplan and Meier [22]. Differences between survival curves were tested for statistical significance using the two-tailed logrank test. The Cox proportional hazard model [23] was used for the univariate and multivariate analyses to evaluate the variables under the "Prognostic factors" section to assess their impact on post-APSCHT OS and PFS times. The choice of optimal cut-off for A-LMR, A-ALC, A-AMC, ALC-15, AMC-15, and LMR-15 to assess survival was based on their utility as a marker for the clinically relevant binary outcome of death/survival using the receiver operating characteristic (ROC) curves and area under the curve (AUC). The binary clinical outcome (death/survival) was established at 5 years post-APHSCT. Patients were classified as "alive/censored" when followup time was greater than 5 years and "death" for patients known to have died before this time point [24]. A $k$-fold cross-validation with $k$ values of 10 was performed to validate the results of A-LMR, A-ALC, A-AMC, ALC-15, AMC-15, and LMR-15. Based on this analysis, crossvalidation $A U C$ by the ROC was produced, representing the discriminating accuracy of A-LMR, A-ALC, A-AMC, ALC-15, AMC-15, and LMR-15 for the binary clinical outcomes of death/survival. To assess the reproducibility of the cut-off value for A-LMR obtained by the ROC curves, the relationship between A-LMR as a continuous variable and the logarithm of the hazard ratio was explored using the Cox proportional hazard restricted cubic spline regression in regard to OS and PFS. The cut-off value was chosen at the point where the A-LMR value caused the hazard ratio to change from favorable to unfavorable.

$X^{2}$ tests and Fisher exact tests were used to determine relationships between categorical variables as appropriate. The Wilcoxon rank test was used to determine associations between continuous variables and categories, and nonparametric tests were used to evaluate associations for continuous variables. All $p$ values represented were twosided, and statistical significance was declared at $p<0.05$.

\footnotetext{
Abbreviations

A-ALC: autograft absolute lymphocyte count; A-AMC: autograft absolute monocyte count; ALC-15: day 15 absolute lymphocyte count post-autologous peripheral hematopoietic stem cell transplantation; A-LMR: autograft lymphocyte/monocyte ratio; AMC-15: day 15 absolute monocyte count post-autologous peripheral hematopoietic stem cell transplantation; APHSCT: autologous peripheral hematopoietic stem cell transplantation; AUC: area under the curve; BEAM: BCNU, etoposide, cytarabine, and melphalan; Cl: confidence interval; CR: complete response; IPI: International Prognostic Index; LDH: lactate dehydrogenase; LMR-15: day 15 lymphocyte/monocyte ratio post-autologous peripheral hematopoietic
} 
stem cell transplantation; OS: overall survival; PFS: progression-free survival; PR: partial response; ROC: receiver operating characteristic.

\section{Competing interests}

The authors declare that they have no competing interests.

\section{Authors' contributions}

LFP = conceived the concept and design, acquisition of data, analysis and interpretation of data, and drafting and revising of the manuscript; DJI, SMA, $I N M, P B J$, and $\mathrm{WJH}=$ drafting and revising of the manuscript; and SNM = analysis and interpretation of data and drafting and revising of the manuscript. All authors read and approved the final manuscript.

Received: 14 May 2015 Accepted: 24 June 2015

Published online: 03 July 2015

\section{References}

1. Wilcox RA, Ristow K, Habermann TM, Inwards DJ, Micallef IN, Johnston PB, et al. The absolute monocyte and lymphocyte prognostic score predicts survival and identifies high risk patients in diffuse large B- cell lymphoma. Leukemia. 2011;25(9):1502-9.

2. Porrata LF, Ristow K, Habermann TM, Witzig TE, Colgan JP, Inwards DJ, et al. Peripheral blood absolute lymphocyte/monocyte ratio during rituximab, cyclophosphamide, doxorubicin, vincristine, and prednisone treatment cycles predicts clinical outcomes in diffuse large B cell lymphoma. Leuk Lymphoma. 2014;55(12):2728-38.

3. Aoki K, Tabata S, Yonetani N, Matsushita A, Ishikawa T. The prognostic impact of absolute lymphocyte and monocyte count at diagnosis of diffuse large B-cell lymphoma in the rituximab era. Acta Haematol. 2013;130(4):242-6.

4. Kumagai S, Tashima M, Fujikawa J, Iwasaki M, Iwamoto Y, Sueki Y, et al. Ratio of peripheral blood absolute lymphocyte count to absolute monocyte count at diagnosis is associated with progression-free survival in follicular lymphoma. Int J Hematol. 2014;99:737-42.

5. Markovic O, Popovic L, Marisavljevic D, Jovanovic D, Filipovic B, Stanisavljevic D, et al. Comparison of prognostic impact of absolute lymphocyte count, absolute monocyte count, absolute lymphocyte/ absolute monocyte count prognostic score and ratio in patients with diffuse large B-cell lymphoma. Eur J Intern Med. 2014;25(3):296-302.

6. Huang JJ, Li YJ, Xia Y, Wang Y, Wei WX, Zhu YJ, et al. Prognostic significance of peripheral monocyte count in patients with extranodal natural killer/T cell lymphoma. BMC Cancer. 2013;13:222.

7. Mitrovic Z, Perry AM, Suzumiya J, Armitage JO, Au WY, Coiffier B, et al. The prognostic significance of lymphopenia in peripheral T cell and natural killer/T cell lymphomas: a study of 826 cases from the International Peripheral T cell lymphoma project. Am J Hematol. 2012;87(8):790-4.

8. Bari A, Tadmor T, Sacchi S, Marcheselli L, Liardo EV, Pozzi S, et al. Monocytosis has adverse prognostic significance and impacts survival in patients with T-cell lymphomas. Leuk Res. 2013;37:619-23.

9. Porrata LF, Gertz MA, Inwards DJ, Litzow MR, Lacy MQ, Tefferi A, et al. Early lymphocyte recovery predicts superior survival after autologous hematopoietic stem cell transplantation in multiple myeloma or nonHodgkin's lymphoma. Blood. 2001;98:579-85.

10. Porrata LF, Inwards DJ, Ansell SM, Micallef IN, Johnston PB, Gastineau D, et al. Early lymphocyte recovery predicts superior survival after autologous stem cell transplantation in non-Hodgkin lymphoma: a prospective study. Biol Blood Marrow Transplant. 2008;14:807-16.

11. Kim H, Sohn HJ, Kim SE, Kang HJ, Park S, Kim S, et al. Lymphocyte recovery as a positive predictor of prolonged survival after autologous peripheral blood stem cell transplantation in T-cell non-Hodgkin's lymphoma. Bone Marrow Transplant. 2004;34(1):43-9.

12. Porrata LF, Litzow MR, Inwards DJ, Gastineau DA, Moore SB, Pineda AA, et al. Infused peripheral blood autograft absolute lymphocyte count correlates with day 15 absolute lymphocyte count and clinical outcome after autologous peripheral hematopoietic stem cell transplantation in nonHodgkin's lymphoma. Bone Marrow Transplant. 2004;33(3):291-8.

13. Porrata LF, Gertz MA, Geyer SM, Litzow MR, Gastineau DA, Moore SB, et al. The dose of infused lymphocytes in the autograft directly correlates with clinical outcome after autologous peripheral blood hematopoietic stem cell transplantation in multiple myeloma. Leukemia. 2004;18(6):1085-92.
14. Hiwase DK, Hiwase S, Bailey M, Bollard G, Schwarer AP. Higher infused lymphocyte dose predicts higher lymphocyte recovery, which in turn, predicts superior overall survival following autologous hematopoietic stem cell transplantation for multiple myeloma. Biol Blood Marrow Transplant. 2008;14:116-24.

15. Porrata LF, Inwards DJ, Ansell SM, Micallef IN, Johnston PB, Hogan WJ, et al. Day 15 peripheral blood lymphocyte/monocyte ratio post-autologous peripheral hematopoietic stem cell transplantation and survival in diffuse large B-cell lymphoma. J Stem Cell Res Ther. 2011;1:2. http://dx.doi.org/10.4172/21577633.1000103.

16. Porrata LF, Inwards DJ, Ansell SM, Micallef IN, Johnston PB, Hogan WJ, et al. Infused autograft lymphocyte to monocyte ratio and survival in diffuse large B-cell lymphoma. Biol Blood Marrow Transplant. 2014;20(11):1804-12.

17. Porrata LF, Inwards DJ, Ansell SM, Micallef IN, Johnston PB, Hogan WJ, et al. Infused autograft lymphocyte to monocyte ratio predicts survival in classical Hodgkin lymphoma. J Blood Med. 2015;6:45-53.

18. Wilcox RA, Wada DA, Ziesmer SC, Elsawa SF, Comfere NI, Dietz AB, et al. Monocytes promote tumor cell survival in T-cell lymphoproliferative disorders and are impaired in their ability to differentiate into mature dendritic cells. Blood. 2009;1 14(14):2936-44.

19. Ansell K, Porrata LF. Autograft monocytes: the bad humors of autologous peripheral blood hematopoietic stem cell transplantation. J Stem Cell Res Ther. October 12 2013; 53: http://dx.doi.org/10.4172/2157-7633.53-005.

20. Ansell SM, Habermann TM, Kurtin PJ, Witzig TE, Chen MG, Li CY, et al. Predictive capacity of the international prognostic factor index in patients with peripheral T-cell lymphoma. J Clin Oncol. 1997;15(8):2296-301.

21. Cheson BD, Pfistner B, Juweid ME, Gascoyne RD, Specht L, Horning SJ, et al. Revised response criteria for malignant lymphoma. J Clin Oncol. 2007;25(5):579-86.

22. Kaplan E, Meier P. Nonparametric estimation from incomplete observations. J Am Stat Assoc. 1958;53:457-81.

23. Cox DR. Regression models and life-tables. J R Stat Soc (B). 1972;34:187-202.

24. Tzankov A, Zlobec I, Went P, Robl H, Hoeller S, Dirnhofer S. Prognostic immunophenotypic biomarker studies in diffuse large B cell lymphoma with special emphasis on rational determination of cut-off scores. Leuk Lymphoma. 2010;51(2):199-212.

\section{Submit your next manuscript to BioMed Central and take full advantage of:}

- Convenient online submission

- Thorough peer review

- No space constraints or color figure charges

- Immediate publication on acceptance

- Inclusion in PubMed, CAS, Scopus and Google Scholar

- Research which is freely available for redistribution 